\title{
DOSSIÊ: EXPANSÃO E DESAFIOS DA QUALIDADE NA EDUCAÇÃO SUPERIOR BRASILEIRA
}

\section{APRESENTAC̣ÃO}

Nas últimas três décadas, a educação superior tem enfrentado grandes desafios, os quais produziram transformações significativas no seu escopo de atuação, na sua governança, na produção e na disseminação de conhecimento, nas relações com as maiores economias e sociedades nacionais, regionais e globais. De acordo com Boaventura Souza Santos, essas transformações fazem parte de uma transição paradigmática ${ }^{1}$ mais ampla, enfrentada por todas as sociedades e as universidades.

Esses desafios são de diversas origens, entre os quais se destacam: (i) o cenário de desigualdades sociais, que configura a educação superior, no mundo e no país, como um campo que exige avanços na direção da inclusão social; (ii) o papel desempenhado por esse campo no processo de adequação de projetos políticos nacionais à atual ordem mundial; (iii) a definição de políticas traduzidas em programas, projetos e planos educacionais visando à formulação de propostas que orientem a expansão e o acesso; iv) a definição de políticas que assegurem condições para que isso ocorra com a qualidade desejada e necessária; e v) a busca de equilíbrio nas tensões presentes na educação superior, resultantes do embate entre as demandas da economia do conhecimento e as oriundas de outros setores da sociedade.

No caso brasileiro, a questão da expansão da educação superior tem ocupado grande centralidade no debate político, tendo estado esta relação presente na elaboração do Plano Nacional de Educação 2014-2024, em especial no que foi estipulado nas metas 12 e 13. No primeiro caso, há a propositura de elevação da taxa bruta e líquida de matrícula, assegurada a qualidade da oferta, e a expansão de novas matrículas no segmento público; e, no segundo caso, o plano propõe como alvo elevar a qualidade da educação superior e a proporção de mestres e doutores em exercício no sistema.

Em termos acadêmicos, essa diversidade de questões tem sido objeto de diversos seminários e publicações de artigos, que demonstram a sua relevância. Ao traduzir questões dessa natureza,

http://dx.doi.org/10.1590/0102-4698032043 
o presente dossiê tem por objetivo apresentar alguns recortes aplicados ao tratamento do tema, sem, contudo, pretender abarcar a complexidade envolvida na produção do conhecimento sobre as políticas para a educação superior.

Este dossiê se insere no escopo dos estudos que vêm sendo desenvolvidos no Observatório da Educação da Capes: "Políticas da Expansão da Educação Superior no Brasil”, conduzido por integrantes da Rede Universitas/Br (www.redeuniversitas.com.br), rede acadêmica que conta com pesquisadores de universidades e diferentes instituições públicas e privadas de educação superior de todas as regiões do país, promovendo a pesquisa e a interlocução entre pares na área das políticas da educação superior. Na sua maioria, esses pesquisadores são membros do Grupo de Trabalho Política de Educação Superior, da Associação Nacional de Pós-Graduação e Pesquisa em Educação (ANPEd).

A Rede Universitas/Br tem promovido diversos seminários nacionais e tem diversas publicações coletivas, entre livros, artigos e dossiês de periódicos. Sua constituição tem proporcionado a formação de grupos de pesquisa, a criação de linhas de pesquisa em programas de pós-graduação, além de estar contribuindo para a formação de estudantes nos diversos níveis da educação superior. Os pesquisadores dessa rede têm buscado aprofundar e ampliar análises, produções e ações acadêmicas acerca do atual processo de expansão da educação superior no Brasil, sempre atuando de maneira articulada às políticas nacionais e internacionais, características da sociedade mundializada, e considerando suas repercussões para esse nível educacional.

Os artigos que integram este dossiê resultam tanto de estudos empíricos quanto do tratamento de fontes documentais e da análise de dados coletados em estatísticas oficiais produzidas, entre outras fontes, pelo Instituto Nacional de Estudos e Pesquisas Educacionais Anísio Teixeira (INEP). A reflexão desenvolvida nos estudos leva em conta a heterogeneidade do campo da educação superior brasileira, composto por segmentos institucionais dotados de características distintas e peculiares. A heterogeneidade e os desafios atualmente enfrentados pelas instituições que atuam nesse campo levam ao exame de como ele vem se reconfigurando.

O conjunto de artigos que integram o dossiê busca realizar um exame mais detalhado das principais tendências que têm sido reveladas a respeito da temática da expansão da educação superior brasileira, de forma a contribuir para a ampliação do conhecimento já produzido. Os artigos representam, assim, um quadro referencial de análise acerca 
dos dilemas implícitos à expansão da educação superior no país, bem como reflexões desenvolvidas com o objetivo de compreender e desvelar os desafios que se apresentam nesse processo.

Articuladas ao cenário mais amplo em que esses dilemas ocorrem, despontam duas indagações que, entre outras, interligam as discussões subjacentes aos artigos aqui apresentados: (i) Quais são as tendências atuais de reconfiguração do campo da educação superior brasileira, em especial da universidade, em função das demandas sociais e das políticas educacionais definidas para o setor a partir da reforma do Estado, em curso desde a segunda metade da década de 1990? (ii) Como garantir uma expansão do acesso que associe o aumento da oferta de vagas ao cumprimento da exigência de qualidade da educação superior brasileira, a ser garantida por meio de uma avaliação contínua e concebida na perspectiva formativa? Questões como essas justificam as reflexões propostas pelos autores e ganham relevância à proporção que se consideram, por um lado, a tendência histórica presente na evolução da educação superior do país de restrição da participação do setor público, com consequente incentivo à expansão da oferta de vagas pelo setor privado, e, por outro, o atendimento às exigências de conjugar acesso e qualidade.

É nesse cenário interpretativo que ganha relevância a compreensão tanto do processo de expansão da educação superior do país nas duas últimas décadas como das relações desse processo com as políticas de acesso e de qualidade para o sistema. Para tanto, consideram-se as múltiplas conexões presentes na dinâmica de um campo tão diversificado, buscando-se analisar criticamente a conjuntura atual e seus impactos para a educação superior.

Assim sendo, os artigos que integram o dossiê abrangem diversos aspectos da educação superior. José Vieira de Sousa, Ivanildo Ramos Fernandes e Otília Maria Lúcia Barbosa Seiffert discutem indicadores de qualidade para a educação superior com base na análise de cursos de graduação considerados como de alta qualidade. Vera Lúcia Jacob Chaves e Nelson Cardoso Amaral analisam a política de expansão da educação superior sob o ponto de vista do financiamento do setor privado, via Fundo de Financiamento Estudantil (FIES) e Programa Universidade para Todos (ProUni). João Ferreira de Oliveira e Karine Nunes de Moraes analisam as tensões, as tendências e os desafios da produção do conhecimento na universidade pública. Carla Vaz dos Santos Ribeiro e Denise Bessa Léda abordam o trabalho docente no contexto de enfrentamento do gerencialismo presente nas universidades federais brasileiras, com ênfase nas suas repercussões na 
subjetividade docente. Arlete Maria Monte de Camargo e Alda Maria Duarte Araújo Castro analisam a relação que vem se operando entre a expansão da educação superior e a formação de professores nos estados do Pará e do Rio Grande do Norte. Salomão Antônio Mufarrej Hage, Hellen do Socorro de Araújo Silva e Márcia Bittencourt Brito focalizam a educação superior do campo e os desafios para a consolidação dessa recente modalidade de licenciatura. Andréia da Silva Quintanilha Sousa e Carina Elizabeth Maciel investigam a permanência e a evasão de estudantes dos cursos a distância oferecidos pela Universidade Aberta do Brasil (UAB). Deise Mancebo, João dos Reis Silva Júnior e Daniel Schugurensky abordam o tema da expansão da educação superior sob uma perspectiva abrangente, buscando situar esse nível de educação no Brasil diante da mundialização do capital.

O conjunto dos oito artigos que formam o dossiê constitui um convite à reflexão de leitores e pesquisadores interessados em explorar e melhor compreender o campo da educação superior brasileira, considerando os muitos desafios nele presentes. As reflexões propostas contribuem para construir olhares diferenciados e críticos sobre a complexidade e a heterogeneidade desse campo, frente às profundas transformações que estão em curso nos cenários nacional e mundial.

Belo Horizonte, dezembro de 2016

\author{
Maria do Carmo de Lacerda Peixoto \\ Faculdade de Educação da Unversidade Federal \\ de Minas G erais, Belo Horizonte-MG, Brasil \\ José Vieira de Sousa \\ Faculdade de Educação da Universidade de \\ Brasília, Brasília-D F, Brasil
}

NOTA

${ }^{1}$ SANTOS, B. S. A crítica da razão indolente: contra o desperdício da experiência. São Paulo: Cortez, 2001. 